\title{
Appendix: Participants
}

Respondents from Chorlton

\begin{tabular}{|c|c|c|c|c|c|}
\hline & $\begin{array}{l}\text { Country } \\
\text { of birth }\end{array}$ & $\begin{array}{l}\text { Ethnic } \\
\text { origin }\end{array}$ & Age & $\begin{array}{l}\text { Married } \\
\text { status }\end{array}$ & $\begin{array}{l}\text { Employment and } \\
\text { highest level of } \\
\text { education }\end{array}$ \\
\hline Ann and Cliff & Britain & White & $\begin{array}{l}\text { Ann: } 48 \\
\text { Cliff: } 50\end{array}$ & Married & $\begin{array}{l}\text { Ann: Accountant } \\
\text { (University BA) } \\
\text { Cliff: NHS manager } \\
\text { (University BA) }\end{array}$ \\
\hline Cindy & Britain & White & 45 & Married & $\begin{array}{l}\text { Social work } \\
\text { manager } \\
\text { (University BA) }\end{array}$ \\
\hline Fiona & Britain & White & 43 & Married & $\begin{array}{l}\text { Freelance project } \\
\text { manager } \\
\text { (University) }\end{array}$ \\
\hline Halima & Britain & $\begin{array}{l}\text { South } \\
\text { Asian / } \\
\text { Pakistani }\end{array}$ & 40 & Married & $\begin{array}{l}\text { Homemaker } \\
\text { (A levels) }\end{array}$ \\
\hline Harrison & Britain & White & 43 & Married & $\begin{array}{l}\text { Homemaker } \\
\text { (formerly university } \\
\text { lecturer and in } \\
\text { advertising) } \\
\text { (University BA) }\end{array}$ \\
\hline Jas and Tej & Britain & South Asian & $\begin{array}{l}\text { Jas: } 42 \\
\text { Tej: } 4 \mathrm{I}\end{array}$ & Divorced & $\begin{array}{l}\text { Managers } \\
\text { (University BA) }\end{array}$ \\
\hline Jasmine & Britain & South Asian & 39 & Divorced & $\begin{array}{l}\text { Family support and } \\
\text { outreach worker } \\
\text { (A levels) }\end{array}$ \\
\hline Kelly & Britain & White & 40 & Married & $\begin{array}{l}\text { Primary school } \\
\text { teacher } \\
\text { (University BA) }\end{array}$ \\
\hline Ken and Fran & Britain & White & Both 43 & Married & $\begin{array}{l}\text { Ken: courier; } \\
\text { College } \\
\text { Fran: midwife; } \\
\text { (University BA) }\end{array}$ \\
\hline
\end{tabular}




\section{Appendix: Participants}

\begin{tabular}{|c|c|c|c|c|c|}
\hline & $\begin{array}{l}\text { Country } \\
\text { of birth }\end{array}$ & $\begin{array}{l}\text { Ethnic } \\
\text { origin }\end{array}$ & Age & $\begin{array}{l}\text { Married } \\
\text { status }\end{array}$ & $\begin{array}{l}\text { Employment and } \\
\text { highest level of } \\
\text { education }\end{array}$ \\
\hline Michael & Britain & White & 53 & Married & $\begin{array}{l}\text { Commercial } \\
\text { Manager } \\
\text { (University BA) }\end{array}$ \\
\hline Molly & Britain & White & 44 & Married & $\begin{array}{l}\text { Research technician } \\
\text { (FE college) }\end{array}$ \\
\hline Rebecca & Britain & White & 42 & Married & $\begin{array}{l}\text { Local government } \\
\text { officer (A level) }\end{array}$ \\
\hline Sabah & Britain & South Asian & 34 & Married & $\begin{array}{l}\text { Primary school } \\
\text { nursery play worker } \\
\text { (FE college) }\end{array}$ \\
\hline Samer & Iraq & $\begin{array}{l}\text { Middle } \\
\text { Eastern }\end{array}$ & 45 & Married & $\begin{array}{l}\text { Chemical engineer } \\
\text { (PhD) }\end{array}$ \\
\hline Sara & Britain & White & 45 & Married & $\begin{array}{l}\text { Student (formerly } \\
\text { social worker) } \\
\text { (University BA) }\end{array}$ \\
\hline Terri & Britain & White & 38 & Married & $\begin{array}{l}\text { Health visitor } \\
\text { (University BA) }\end{array}$ \\
\hline
\end{tabular}

\section{Respondents from Cheadle Hulme}

\begin{tabular}{|c|c|c|c|c|c|}
\hline & $\begin{array}{l}\text { Country } \\
\text { of birth }\end{array}$ & $\begin{array}{l}\text { Ethnic } \\
\text { origin }\end{array}$ & Age & $\begin{array}{l}\text { Married } \\
\text { status }\end{array}$ & $\begin{array}{l}\text { Employment and } \\
\text { highest level of } \\
\text { education }\end{array}$ \\
\hline Alia & Britain & South Asian & $4 \mathrm{I}$ & Married & $\begin{array}{l}\text { Homemaker } \\
\text { (FE college) }\end{array}$ \\
\hline Annabel & Britain & White & 43 & Married & $\begin{array}{l}\text { Business woman } \\
\text { (FE college) }\end{array}$ \\
\hline Annette & Britain & White & 45 & Married & $\begin{array}{l}\text { Pre-school teacher } \\
\text { (A levels) }\end{array}$ \\
\hline Bea and Mark & Britain & White & $\begin{array}{l}\text { Bea: } 45 \\
\text { Mark: } \\
47\end{array}$ & Married & $\begin{array}{l}\text { Bea: hairdresser } \\
\text { Mark: driver } \\
\text { (Qualifications not } \\
\text { given) }\end{array}$ \\
\hline Emily & Britain & White & 37 & Married & $\begin{array}{l}\text { Local council worker } \\
\text { (A level) }\end{array}$ \\
\hline Emma & Britain & White & 43 & Divorced & $\begin{array}{l}\text { Secondary school } \\
\text { teacher } \\
\text { (University BA) }\end{array}$ \\
\hline Jen & Britain & White & 46 & Married & $\begin{array}{l}\text { Shopworker } \\
\text { (Qualifications not } \\
\text { given) }\end{array}$ \\
\hline
\end{tabular}


Appendix: Participants

\begin{tabular}{|c|c|c|c|c|c|}
\hline & $\begin{array}{l}\text { Country } \\
\text { of birth }\end{array}$ & $\begin{array}{l}\text { Ethnic } \\
\text { origin }\end{array}$ & Age & $\begin{array}{l}\text { Married } \\
\text { status }\end{array}$ & $\begin{array}{l}\text { Employment and } \\
\text { highest level of } \\
\text { education }\end{array}$ \\
\hline Jessica & Britain & White & 40 & Married & $\begin{array}{l}\text { Childminder } \\
\text { (O levels) }\end{array}$ \\
\hline $\begin{array}{l}\text { Melanie and } \\
\text { Steve }\end{array}$ & Britain & White & $\begin{array}{l}\text { Melanie: } \\
29 \\
\text { Steve: } \\
30\end{array}$ & Married & $\begin{array}{l}\text { Melanie: beauty } \\
\text { therapist } \\
\text { (GCSEs) } \\
\text { Steve: delivery } \\
\text { driver } \\
\text { (GCSEs) }\end{array}$ \\
\hline Meredith & Britain & White & 33 & Married & $\begin{array}{l}\text { Homemaker } \\
\text { (GCSEs) }\end{array}$ \\
\hline Natalie & Britain & White & 37 & Married & $\begin{array}{l}\text { Office worker } \\
\text { (A levels) }\end{array}$ \\
\hline Rachel & Britain & White & 27 & Single & $\begin{array}{l}\text { Student Nurse } \\
\text { (A levels) }\end{array}$ \\
\hline Runa & Britain & South Asian & 38 & Divorced & $\begin{array}{l}\text { Unemployed } \\
\text { (previously worked } \\
\text { in admin) } \\
\text { (University BA) }\end{array}$ \\
\hline Saira & Pakistan & South Asian & 39 & Married & $\begin{array}{l}\text { Works at the } \\
\text { airport } \\
\text { (High school) }\end{array}$ \\
\hline Samantha & Britain & White & 44 & Married & $\begin{array}{l}\text { Nurse } \\
\text { (University BA) }\end{array}$ \\
\hline Sharon & Britain & White & 39 & Widow & $\begin{array}{l}\text { Civil servant } \\
\text { (FE college) }\end{array}$ \\
\hline Stan & China & Asian & 46 & Married & $\begin{array}{l}\text { Waiter } \\
\text { (High school) }\end{array}$ \\
\hline
\end{tabular}

\section{Respondents from Whalley Range}

\begin{tabular}{|c|c|c|c|c|c|}
\hline & $\begin{array}{l}\text { Country } \\
\text { of birth }\end{array}$ & $\begin{array}{l}\text { Ethnic } \\
\text { origin }\end{array}$ & Age & $\begin{array}{l}\text { Married } \\
\text { status }\end{array}$ & $\begin{array}{l}\text { Employment and } \\
\text { highest level of } \\
\text { education }\end{array}$ \\
\hline Fauzia & Bangladesh & South Asian & 39 & $\begin{array}{l}\text { Married } \\
\text { (husband } \\
\text { often } \\
\text { abroad) }\end{array}$ & $\begin{array}{l}\text { Homemaker } \\
\text { (High school) }\end{array}$ \\
\hline Helen & Britain & $\begin{array}{l}\text { African } \\
\text { Caribbean }\end{array}$ & 36 & Married & $\begin{array}{l}\text { Teaching assistant } \\
\text { (A levels) }\end{array}$ \\
\hline Leyla & Somali & African & 34 & Married & $\begin{array}{l}\text { Homemaker } \\
\text { (High school) }\end{array}$ \\
\hline
\end{tabular}




\section{Appendix: Participants}

\begin{tabular}{|c|c|c|c|c|c|}
\hline & $\begin{array}{l}\text { Country } \\
\text { of birth }\end{array}$ & $\begin{array}{l}\text { Ethnic } \\
\text { origin }\end{array}$ & Age & $\begin{array}{l}\text { Married } \\
\text { status }\end{array}$ & $\begin{array}{l}\text { Employment and } \\
\text { highest level of } \\
\text { education }\end{array}$ \\
\hline $\begin{array}{l}\text { Marion } \\
\text { (grandmother } \\
\text { and guardian) }\end{array}$ & Britain & White & 54 & Married & $\begin{array}{l}\text { Domestic worker } \\
\text { (O levels) }\end{array}$ \\
\hline Nasreen & Britain & South Asian & 33 & Married & $\begin{array}{l}\text { Translator } \\
\text { (FE college) }\end{array}$ \\
\hline Nighat & Tanzania & South Asian & 42 & Married & $\begin{array}{l}\text { Homemaker } \\
\text { (High School) }\end{array}$ \\
\hline Noreen & Pakistan & South Asian & $4 \mathrm{I}$ & $\begin{array}{l}\text { Married } \\
\text { (husband } \\
\text { abroad) }\end{array}$ & $\begin{array}{l}\text { Homemaker } \\
\text { (formerly teacher in } \\
\text { Pakistan) } \\
\text { (High school) }\end{array}$ \\
\hline Nusrat & Pakistan & South Asian & 50 & Separated & $\begin{array}{l}\text { Homemaker } \\
\text { (High school) }\end{array}$ \\
\hline Pam & Britain & $\begin{array}{l}\text { African } \\
\text { Caribbean }\end{array}$ & 40 & Separated & $\begin{array}{l}\text { Midwife } \\
\text { (University BA) }\end{array}$ \\
\hline Sadia & Libya & $\begin{array}{l}\text { Middle } \\
\text { Eastern }\end{array}$ & 42 & Divorced & $\begin{array}{l}\text { Teacher in a } \\
\text { mosque } \\
\text { (High school) }\end{array}$ \\
\hline Serena & Britain & $\begin{array}{l}\text { African } \\
\text { Caribbean }\end{array}$ & 46 & Married & $\begin{array}{l}\text { Nurse } \\
\text { (University BA) }\end{array}$ \\
\hline Shahida & Pakistan & South Asian & 37 & $\begin{array}{l}\text { Married } \\
\text { (husband } \\
\text { abroad) }\end{array}$ & $\begin{array}{l}\text { Homemaker } \\
\text { (High school) }\end{array}$ \\
\hline Simal & Turkey & Turkish & 44 & Married & $\begin{array}{l}\text { Homemaker } \\
\text { (High school) }\end{array}$ \\
\hline Winnie & Ghana & $\begin{array}{l}\text { Black } \\
\text { African }\end{array}$ & 46 & Married & $\begin{array}{l}\text { Fashion designer } \\
\text { (University BA) }\end{array}$ \\
\hline
\end{tabular}

